\title{
Curso para pais grávidos: expectativas das gestantes/acompanhantes e dos profissionais envolvidos
}

Marcio Hideki Setogutti Nanamura', Luiz Ferraz de Sampaio Neto²

\section{Resumo}

Cursos para gestantes pretendem diminuir dúvidas e humanizar o atendimento, contrapondo-se ao pré-natal, considerado impessoal e muito técnico. Contudo, os benefícios dessas atividades educativas na saúde nem sempre são descritos como eficientes. Neste estudo pretendemos avaliar curso oferecido por empresa de saúde suplementar, propor mudanças e discutir novo modelo de curso. Participaram da pesquisa dezesseis gestantes e quinze acompanhantes que assistiram ao curso e os quatro profissionais que promovem a aula. As gestantes e seus acompanhantes responderam questionário antes e após a palestra que indagava dados pessoais e sobre temas abordados na aula, seguido por dinâmica em grupo, na qual os participantes realizaram colagens a partir de duas questões motivadoras sobre experiências no curso e expectativas do parto. O teste " $t$ " de Student caracterizou mudanças de conceito após o curso nos temas: orientação sobre a gestação, sobre o parto, tipos de parto, cuidados com o recém-nascido, funcionamento da assistência ao parto no hospital, quando devem ir ao hospital. $\mathrm{Na}$ análise qualitativa, predominaram sentimentos associados ao medo e à insegurança. Concluímos que o curso foi bem avaliado pelos participantes, mas foi sugerido que teria sido mais bem aproveitado se fosse oferecido a grupos com idades gestacionais próximas; deveria ser incluída uma avaliação inicial/final e, em relação à metodologia, seria mais adequado usar dinâmicas de grupos, pois permitiria o compartilhamento de saberes sobre os temas.

\section{Palavras-chave}

Centros de Assistência à Gravidez e ao Parto. Assistência Prénatal. Educação em Saúde.

1. Mestrando em Educação na Pontifícia Universidade Católica de São Paulo, Brasil; médico ginecologista e obstetra. E-mail: marcionanamura@gmail.com.

2. Doutor em Medicina pela Universidade de São Paulo, Brasil; professor titular da Pontifícia Universidade Católica de São Paulo, Brasil. E-mail: Ifsampaio@pucsp.br. 


\title{
Workshops for pregnant parents: expectations of pregnant women/companions and professionals involved
}

\author{
Marcio Hideki Setogutti Nanamura*, Luiz Ferraz de Sampaio Neto**
}

\begin{abstract}
Workshops for pregnant women seek to solve doubts and humanize care as opposed to impersonal and very technical prenatal care. However, the benefits of these health education activities are not always described as efficient. In this study we intend to evaluate a course already offered by a supplementary health company - propose changes and discuss a new course model. Sixteen pregnant women and fifteen companions attended the course and the four professionals who promoted the class participated in the study. The pregnant women and their companions answered a questionnaire before and after the lecture, which inquired about personal data and about topics covered in the class followed by group dynamics where the pregnant women and their companions performed collages based on two motivating questions about experiences in the course and expectations of the childbirth. Student's " $\mathrm{t}$ " test characterized a change in the concept after the course in the following subjects: orientation on gestation, on delivery, type of delivery, care with the newborn, functioning of childbirth care in the hospital, when one should go to the hospital. Feelings associated with fear and insecurity predominated in the qualitative analysis. We concluded that the course was well evaluated by the meeting participants, but it was suggested that it would be better used if it was offered to groups with similar gestational ages; an initial/final evaluation should also be included and, about the methodology, it would be more appropriate to use group dynamics, as it would allow the sharing of knowledge about the themes.
\end{abstract}

\section{Keywords}

Birthing centers. Prenatal Care. Health Education.

\footnotetext{
* MSc student in Education, Catholic Pontifical University of São Paulo, State of São Paulo, Brazil; obstetrician and gynecologist. E-mail: marcionanamura@gmail.com.

** PhD in Medicine, University of São Paulo, professor at Catholic Pontifical University of São Paulo, State of São Paulo, Brazil. E-mail: Ifsampaio@pucsp.br.
} 


\section{Introdução}

Segundo Rezende (2001), a obstetrícia progrediu muito lentamente em relação às outras ciências médicas. Uma justificativa para esse fato deve-se ao atendimento prestado às gestantes e à assistência ao parto serem guiados, desde a Antiguidade, por pessoas experientes, sem um adequado preparo teórico. Geralmente eram parteiras práticas e mulheres "curiosas" com boa vontade que recebiam informações de geração em geração, transmitindo práticas de assistência à gravidez e ao parto sem cunho científico baseadas em crendices e feitiços. $\mathrm{O}$ fenômeno da parturição se sucedia na residência da mulher, lugar onde as parteiras e a parturiente trocavam conhecimentos e descobriam afinidades.

A partir da metade do século XIX, com o desenvolvimento da obstetrícia como área acadêmica do conhecimento, a assistência empírica prestada por mulheres durante o ciclo gravídico-puerperal perdeu seu espaço, pois se iniciou uma intensa disputa entre as classes médica e das parteiras práticas, e, estas, tiveram o domínio do saber na arte de assistir ao parto e ao nascimento reduzido (SCHIRMER et al., 2002). Essas mudanças culminaram com novos paradigmas em obstetrícia, pois, nos últimos anos, a gestação e o ato de parir, considerados como fenômenos naturais e fisiológicos, foram transformados em um processo patológico e medicalizado, alterando sua essência original de evento de mãe e filho em acontecimento social (OLIVEIRA et al., 2002).

É inegável que houve muitos ganhos com a institucionalização do parto, como a melhor assepsia, que previne infecção puerperal e redução na morte materna, e a possibilidade de oferecer acompanhamento da assistência à parturição com o pronto atendimento ao recémnascidode risco por equipe médica especializada. Entretanto, com a supervalorização dos aspectos técnicos do nascimento, a ênfase exagerada na fisiologia e patologia negligenciou os aspectos psicoemocionais e sociais, passando a negar à parturiente seu direito de experimentá-lo de acordo com seus significados adquiridos culturalmente. Com a institucionalização do parto, também houve um crescimento cada vez maior no número de partos operatórios em detrimento do parto normal. Paradoxalmente, esse índice tem favorecido as altas taxas de morbimortalidade maternoinfantil decorrente das cesáreas (BRASIL, 2001). Assim, no final dos anos de 1990, pelo alto índice de partos hospitalares, e como consequência dos altos números de partos operatórios, surge a discussão em torno do resgate da assistência obstétrica individualizada, que culminou na organização do Programa de Humanização no Pré-natal e Nascimento pelo Ministério da Saúde. Esse programa baseia-se em um conjunto de procedimentos que visam à promoção do nascimento saudável e à prevenção da morbimortalidade materna e perinatal norteados essencialmente pela ideia de que parto não é doença e no respeito à dignidade e liberdade da mulher como condutora de seu próprio processo de parturição, cabendo a ela escolher onde, como e com que profissional quer realizar seu parto (BRASIL, 2001). Em 2011, o Ministério da Saúde lançou o Programa Rede Cegonha, que objetiva a melhora da assistência materno-infantil por meio da implantação de modelo de atenção à saúde da mulher e da criança, de modo a garantir acesso, acolhimento e resolutividade e promover a diminuição dos índices de mortalidade materna e infantil (BRASIL, 2001).

A gravidez e o parto representam eventos especiais na vida da mulher, porém a sensação de tornar-se mãe confunde-se, muitas vezes, com incertezas, medos e inseguranças. É um evento biopsicossocial, pois está cercado de valores culturais, sociais e emocionais. A mulher e seu companheiro, assim como os demais integrantes 
do núcleo familiar, vivenciam momentos significativos nesse período que repercutem por toda a vida. Neste cenário, a participação do pai de maneira mais ativa é muito recente, uma vez que a percepção pelo pai do que acontece durante o período gravídico-puerperal é diferente do que ocorre com as gestantes. Ele costuma ser inserido no processo à medida que o feto apresenta movimentação perceptível e que o crescimento do abdome gravídico pode ser constatado por um observador (TEDESCO et al., 2004; STRAPASSON, 2011).

O curso para pais grávidos, que deve ser oferecido para grupos de gestantes e respectivos parceiros, promove um processo educativo flexível, dinâmico, complexo, terapêutico e ético que se constrói a partir das interações entre os seres humanos. Nele, quem ensina aprende e quem aprende ensina, havendo troca de conhecimentos e experiências, uma vez que cada ser que interage, o faz com suas ideias, valores, atitudes e experiências. O processo educativo é um instrumento de socialização de saberes, de promoção da saúde e de prevenção de doenças. Pode contribuir para a autonomia no agir, possibilitando aos envolvidos tornarem-se sujeitos ativos, na medida em que contribui para valorizar capacidades, autoestima, autoconfiança e autorrealização. É um instrumento de transformação, de construção e reconstrução da realidade, de posturas e atitudes, tornando o mundo e a história mais humanos (ZAMPIERI, 2010). A promoção da saúde tem estreita relação com a educação em saúde que se estabelece a partir da participação popular, de suas necessidades, de seu estilo de vida, crenças e valores, desejos, opções, vivências, da subjetividade e intersubjetividades, no contexto cultural, social, político em que se vive. Essa participação exige envolvimento, compromisso, solidariedade enquanto construção cotidiana de decisões em conjunto estabelecida com todos que participam do processo educativo, que mantêm o compromisso de trocar experiências, vivências, conhecimento, todos em sua forma diferentes porque as histórias de cada um foram construídas diferentemente (SANTOS; PENNA, 2009).

A aceitação dessa diferença talvez seja uma das dificuldades do processo educativo, pois pode se tornar um processo longo e, muitas vezes, conflituoso. Como as pessoas são diferentes, as necessidades também o são e isso pode gerar atrito. Mas é justamente na divergência, na busca de soluções conjuntas, na própria alteridade, que as pessoas crescem e, muitas vezes, descobrem que suas necessidades individuais são da coletividade e muitas das necessidades coletivas podem tornar-se suas. É aprender no dia a dia a viver uma "harmonia conflital", presente em todas as relações humanas (MAFFESOLI, 1996).

A educação em saúde participativa não se estabelece, portanto, de forma linear nem imediata. É uma construção cotidiana e coletiva, possivelmente inacabada. Não há receitas nem fórmulas para mudanças de comportamento. É necessário reconhecer que há um caminho extenso a ser percorrido e que as possíveis mudanças não são aquelas que talvez o profissional de saúde pretenda e que nem sempre são visíveis. Não se desejam grandes transformações de ordem política com todas as reivindicações garantidas, mas, é necessário reconhecer como válidas as mudanças que as pessoas são propositoras, pois sempre existem outras possibilidades de agir nos vários espaços da sociedade (GAZZINELLI, 2005).

Por isso, o modelo de educação bancária é criticado, uma vez que considera o educando como depósito de conhecimento que recebe de outro, este detentor do saber, e, neste tipo de dinâmica, não importa o público educador. Ao contrário, o educador deve funcionar como um adubo que faz com que a semente cresça e floresça, tenha vida própria e independente, sendo apenas um potencializador da capacidade 
do ser. O ensinar envolve compaixão, comprometimento, amor, ou seja, não é uma prática fria, distante, impessoal, porém, uma prática envolvente e realizada de forma simples, sem arrogância, pois a simplicidade torna a pessoa melhor, mais gente (FREIRE, 1996).

Desse modo, para que as ações de educação em saúde sejam bem sucedidas, é preciso considerar o contexto cultural dos sujeitos envolvidos no processo, levando-se em conta suas representações sociais a respeito dos aspectos relacionados à saúde. Essas representações, por sua vez, não são tomadas como um sistema fechado, mas sim como um campo aberto que pode se transformar durante as interações indivíduo-indivíduo/ sociedade. De modo geral, as mudanças necessárias para condução dos processos de educação em saúde têm levado os profissionais de saúde a buscar outros referenciais, além dos biológicos, já que se reconhece que as ações que visam uma melhoria na qualidade de vida dos sujeitos estão entrelaçadas com a cultura, ou seja, com estilos de vida, hábitos, rotinas e rituais das pessoas (BOEHS, 2007).

Todavia, para obter conhecimento sobre a cultura dos sujeitos envolvidos nos processos educativos, éprecisotorná-los protagonistasdesse processo. Isso possibilitaria o desenvolvimento de estratégias educativas condizentes com as práticas culturais de determinada comunidade. Ao considerar a educação como um processo de troca, um processo de ensino-aprendizagem, no qual educandos procuram conhecer por meio de diálogo, torna-se relevante que a população participe e que as características dessa população sejam valorizadas no cuidado educativo (SOUZA, 2011).

As dinâmicas populares permitem a criação de vínculos que constroem novos conhecimentos por meio do cooperativismo de saberes entre os participantes, não ficando somente na imposição da ciência, mas proporcionando troca de conceitos entre a academia e a sociedade (ALBERTI, 2014). A educação em saúde pressupõe uma combinação de oportunidades que favorecem a promoção e a manutenção da saúde, não sendo somente uma simples transmissão de conteúdos, comportamentos e hábitos de higiene, mas a adoção de práticas educativas em busca da autonomia dos sujeitos na condução de suas vidas (GENIAKE, 2015).

A partir dessas considerações, os cursos para gestantes são uma forma de educação em saúde, estando inseridos na linha de cuidado à gestante, puérpera e recém-nascido com o intuito de contribuir para promoção da saúde. Os cursos habitualmente discutem aspectos relacionados à importância do pré-natal, aos cuidados com a gestante e com o recém-nascido, ao aleitamento materno e os direitos sociais na maternidade. Para se conseguir esta abordagem tão ampla e complexa, foi necessário articular um trabalho interdisciplinar, envolvendo enfermeiro, obstetra, pediatra, psicólogo e odontólogo.

No Programa Saúde da Família (PSF), as consultas de pré-natal são realizadas pelo médico e pelo enfermeiro, devendo haver um trabalho interdisciplinar que possa resultar em assistência de qualidade, cumprindo os objetivos do pré-natal, que são: prevenir, identificar e/ ou corrigir as intercorrências maternas e fetais, bem como instruir as gestantes no que diz respeito à gravidez, ao parto, ao puerpério e aos cuidados com o recém-nascido. Em outras palavras, além da importância clínica do pré-natal, este se constitui num momento ímpar para realização de medidas educativas, assim como para oferecer apoio emocional e psicológico ao companheiro e a família, para que todos estejam envolvidos no processo de gerar, parir e nascer (MOREIRA, 2007).

Todavia, estudos mostram que as consultas de pré-natal são muito rápidas, focando na técnica do exame obstétrico, fazendo com que possíveis anormalidades mais sutis não sejam percebidas e, sobretudo, impedindo que 
as mulheres possam manifestar suas queixas, dúvidas e medos intrínsecos à gravidez. Com isso, é preciso que os profissionais de saúde criem estratégias educativas, no sentido de sanar estes déficits, muitas vezes, não valorizados, pois frequentemente os médicos se restringem apenas a questão clínica, orgânica durante as consultas de pré-natal. No PSF, foram criados grupos de gestantes para discutir essas questões e poder proporcionar uma assistência de qualidade, sendo formado basicamente pelo médico e enfermeiro (MOREIRA, 2007). Nessa direção, é que se compreendem os motivos que ampliaram os cursos para gestantes para a condição de cursos para "pais grávidos".

Além disso, alguns estudos demonstraram que é muito importante efetuar o diagnóstico de grupos de risco e a profilaxia da depressão pós-parto. Com esse foco, deve-se abordar conceitos relativos à experiência de estar grávida, com nuances que permitam o surgimento de dúvidas relativas a sentimentos de frustração nos cursos de gestantes, para se ater à possibilidade dessa enfermidade após o parto; essa faceta pode propiciar o treinamento da equipe de saúde em questionários com esse objetivo ou a inclusão de profissional psicólogo nos grupos (SAMPAIO NETO; ALVARES, 2013).

A Saúde Suplementar costuma buscar no SUS as boas experiências na atenção à saúde. $\mathrm{Na}$ Unimed de Sorocaba, o curso para pais grávidos iniciou-se em 2009, sendo oferecido periodicamente desde então. Presentemente vem ocorrendo em forma de palestras mensais, onde participam a gestante e um acompanhante, habitualmente o companheiro. Desde a realização dessa atividade educativa aconteceram diferentes versões que incluíam diferentes conteúdos e formas de apresentação. Contudo, a essência do curso aborda a gestação e o parto, principalmente a via de parto, se normal ou cesárea; o aleitamento materno e alguns cuidados com o recém-nascido, sendo ministrado às vezes por médico obstetra e, em todas as versões, contando com a participação de enfermeiro, fonoaudiólogo e nutricionista. O curso tem como objetivo proporcionar aos clientes do sistema Unimed novos conhecimentos relacionados à saúde materna e cuidados na primeira infância. De forma mais específica, procura orientar a gestante nos aspectos relacionados à gestação e primeiros cuidados com o recém-nascido; auxiliar a melhora da saúde materna e procura minimizar as angústias e inseguranças desenvolvidas durante a gestação que podem interferir negativamente nos cuidados com a mãe e bebê; incentivar o aleitamento materno exclusivo até o sexto mês de vida da criança; e estimular a via de parto normal.

As ações são realizadas por meio de palestras com enfermeiros, nutricionistas e fonoaudiólogos que expõem vários temas, desde o pré-natal aos cuidados com o recémnascido. Cada gestante e seu acompanhante são convidados a participar uma única vez no curso durante a gravidez. O convite é feito por meio de publicidade institucional e de informativos direcionados a usuárias grávidas da Unimed de Sorocaba. O conteúdo programático é aberto, mas, nesse único encontro teórico, na forma de aula magistral, serão obrigatoriamente discutidos aspectos relativos às vantagens e desvantagens dos tipos de partos, como será a dinâmica do momento do parto, o papel da equipe multidisciplinar na assistência ao parto e autocuidados com o puerpério e a lactação. Há, ainda, um segundo momento em grupo, quando as pacientes são divididas em subgrupos, formados a partir daqueles que estavam no encontro inicial, e convidadas a visitar o Hospital Unimed de Sorocaba, local do parto. Nesse encontro no hospital, elas são acompanhadas por obstetriz e conhecem a admissão/pré-parto, sala de parto e alojamento da puérpera e concepto.

A despeito de não existir uma investigação cientificamente embasada para caracterizar, é voz corrente que os médicos 
obstetras da Unimed Sorocaba não observam benefícios expressivos da participação de suas pacientes gestantes no curso oferecido pela cooperativa aos seus usuários. Essa impressão é reforçada porque as gestantes também não manifestam muitos elogios ao curso. Da mesma forma, os profissionais envolvidos diretamente nessa atividade acreditam que a fórmula atual seja pouco produtiva.

Nossa hipótese faz pensar que o curso para pais grávidos, na forma como existe hoje, a despeito da boa vontade e capacidade técnica dos profissionais envolvidos, não consegue cumprir seu papel de esclarecimento e de redução das angústias e inseguranças envolvidas na parturição para o público-alvo.

Assim, este estudo pretende avaliar as expectativas da gestante e de seu acompanhante no curso para pais grávidos, investigar também as expectativas dos profissionais envolvidos na elaboração e apresentação do curso e, por último, propor um novo modelo de curso de gestante a ser aplicado na Unimed de Sorocaba a partir do curso já existente.

\section{Casuística e método}

\section{Primeiro momento: atividade teórica}

Casuística: trata-se de um relato de experiência do tipo pesquisa-ação, de natureza exploratória, com abordagem quali/quantitativa por meio da observação. Houve a aprovação pelo Comitê de Ética em Pesquisa (Comitê de Ética em Pesquisa da Faculdade de Ciências e Médicas da Saúde da Pontifícia Universidade Católica de São Paulo, sob o número 1724102/2016) e autorização da Diretoria Administrativa da Unimed de Sorocaba.

Todos os participantes foram esclarecidos a respeito da pesquisa e assinaram o Termo de Consentimento Livre e Esclarecido. Foram incluídos os dados das gestantes, de seus parceiros e/ou de seus acompanhantes (mães, amigas etc.) assinalados nos questionários iniciais para cada um desses subgrupos (gestantes, parceiros e acompanhantes). Foi aplicado também um questionário específico para os profissionais envolvidos (colaboradores) no curso. As informações basicamente caracterizaram dados sociodemográficos. As gestantes deveriam informar idade, estado civil, se já tinham filhos (e quantos), escolaridade, como tiveram conhecimento do curso, se já frequentaram algum curso de preparo para gestação e parto antes, a idade gestacional no momento do curso e o número de consultas feitas até o presente momento na atual gestação. Os parceiros deviam informar idade, escolaridade, como ficaram sabendo do curso, se já frequentaram algum curso para gestante em outra ocasião, se tinham outros filhos de outros relacionamentos, se acompanhavam sua esposa às consultas de pré-natal e se pretendiam estar presente no momento do parto. Os demais acompanhantes deveriam informar qual sua relação com a gestante (mãe, irmã, amiga etc.), escolaridade, o que os motivou a estarem lá, se tinham filhos, se acompanhavam a gestante nas consultas de pré-natal e se pretendiam estar ao lado da gestante no momento do parto.

Também foi perguntado sobre a relevância de se discutir os temas: orientação sobre a gestação; orientação sobre doenças na gestação; orientação sobre exames do prénatal; orientação sobre o parto; orientação sobre o tipo de parto; aprendizagem sobre os primeiros cuidados com o recém-nascido, conhecimentos sobre como funciona a assistência ao parto na Unimed Sorocaba; saber se existe cobrança de honorários para a disponibilidade dos médicos assistirem às gestantes; reconhecimento de quando devem ir ao hospital e aprendizagem de maneiras não medicamentosas de diminuir a dor do parto. Os questionários continham a identificação de quem o preencheu, pois eram necessários para a comparação com o 
questionário avaliativo final. Dessa forma, os parceiros e/ou acompanhantes assinalaram o nome da gestante que acompanham para poder-se montar o "núcleo" de cada uma e permitir a avaliação posterior. As partes finais dos três questionários iniciais eram semelhantes e permitiram avaliar a importância que cada um dos segmentos (gestantes, parceiros e acompanhantes) atribui a alguns temas relacionados ao processo gravídico, parturição e período neonatal. Havia espaço destinado para comentários adicionais.

O questionário destinado aos profissionais envolvidos no curso serviu, sobretudo, para melhor compreender a dinâmica de como foi elaborado e como é desenvolvido o curso para gestantes. Assim, todos os profissionais deveriam responder ao questionário inicial caracterizando sua formação, o tempo que faziam parte do grupo que organiza/ministra os cursos de gestantes, quais seus papéis na operacionalização do curso. Também nos interessou como cada um dos profissionais avalia o curso e como eles imaginam que o público que assiste ao curso avalia o que foi apresentado. Finalmente, questionaram-se quais temas o profissional considera importante apresentar às gestantes e qual a relevância de cada um desses temas. Também havia espaço para comentários adicionais.

Após as atividades educativas e a intervenção da pesquisa, as gestantes e seus parceiros e/ou acompanhantes foram convidados a responder ao questionário final, que pretende recuperar informações sobre aquilo que foi apresentado.

Avaliação estatística: para esta fase do estudo, as informações sociodemográficas dos subgrupos estudados foram transcritas para planilha Microsoft ${ }^{\circledR}$ Excel 2013, sendo estimadas frequência e média, quando pertinente. Em relação à impressão dos temas antes e após o curso para avaliar se houve mudança foi utilizado o teste estatístico " $\mathrm{t}$ " de Student.

\section{Segundo momento: atividade prática}

Após as atividades apresentadas na forma de palestras pelos profissionais que participaram do curso, o grupo de gestantes e seus acompanhantes foi subdividido em dois, pois existia atividade prática de orientação para banho do neonato e ambos, gestante e acompanhante, participariam conjuntamente desta orientação.

Nessa fase do curso, o pesquisador principal permaneceu com metade do grupo, para ter contato mais próximo e coordenar a atividade prática de colagem. Posteriormente, houve a troca dos subgrupos; dessa forma todos participaram de ambas as atividades.

Pelas peculiaridades da temática em questão, que trata de uma fase especial na vida da gestante e de seu parceiro (ou de seu acompanhante), diante das preocupações que surgem com a proximidade do parto, das incertezas de como será seu parto e, especialmente, sobre seu bebê, e a partir das informações contidas em Minayo (2000), a segunda fase do estudo foi realizada com o emprego de método qualitativo. Uma das características da pesquisa qualitativa é fornecer ao pesquisador a possibilidade de captar a maneira pela qual os indivíduos pensam e reagem ante as questões focalizadas, além de auxiliar na compreensão dos sentimentos, dos valores, das atitudes e dos temores das pessoas, explicando suas ações diante de um problema ou situação (ALMEIDA, 2008).

Especificamente para este trabalho, a técnica projetiva utilizada foi a denominada "Desenhos e estórias com tema", desenvolvida por Trinca (1997), que possibilita a manifestação gráfica de um elemento sugerido, cuja ideia é expressapormeiododesenho, quevemcarregado de elementos significativos (ALMEIDA, 2008). Tendo em vista a necessidade de agilidade 
e para facilitar o produto, foi usada a colagem em substituição ao desenho, para obter resposta às questões norteadoras. Em seguida, foi solicitado ao "núcleo" que descrevesse a montagem para que a narrativa fosse analisada em outro momento.

Para permitir a técnica de colagem, foram distribuídas folhas, revistas variadas, canetas coloridas, tesouras e cola para que cada um dos "núcleos" executasse colagem que melhor representasse uma das questões: a) Como você espera que seja seu parto? b) Como foi para você participar hoje deste curso?

Após intervalo de 15 minutos para que se processassem dentro de cada um dos "núcleos", foi solicitado que realizassem colagens que representassem as impressões do curso. Após, foi solicitado que apresentassem publicamente uma narrativa descrevendo seu painel. As narrativas foram gravadas com gravador digital, correlacionando-se com os participantes de cada um dos "núcleos" para posterior análise e correlação com os questionários iniciais e finais.

Análise dos dados: o tratamento das narrativas ocorreu através da transcrição, correlacionando-as com aquilo que foi descrito sobre as imagens das colagens digitalizadas. Nessa fase, buscamos interpretar cada uma das descrições pelos seus criadores, que classificamos em "subtemas", subjacentes às descrições daquilo que pretendiam representar. Essa análise nos permitiu elaborar uma opinião pessoal a partir da interpretação das colagens, além de ser um fator motivador de roda de conversa sobre os temas abordados.

\section{Resultados e Discussão}

O curso teve 31 participantes, dos quais todos participaram do estudo, sendo 16 gestantes e 15 acompanhantes (todos eram os respectivos companheiros). O grupo teve média de idade de 31,90 anos (as gestantes, média de idade de
31,31 anos, e os homens, média de 32,79 anos). Em referência ao estado civil, todos são casados. Em relação a filhos, $87 \%$ não possuem filhos e $23 \%$ os possuem. No tocante ao grau de escolaridade, 25,80\% possuem até nível de pós-graduação, 45,10\% têm ensino superior completo, 6,40\% têm ensino superior incompleto, $19,5 \%$ possuem ensino médio completo e 3,20\% ensino médio incompleto.

Referente à geração, $66,7 \%$ das gestantes são da "geração $X$ " e 33,3\% são da "geração $Y$ ". Classificamos, dessa forma, devido ao fato de que, no mundo de hoje, conforme o momento histórico e econômico existe um perfil para cada geração. Com isso, são descritas as gerações $X$ e a Y. A primeira compreende idades entre 31 e 43 anos e suas características são a apatia política e a busca de um equilíbrio entre o trabalho e a família. Já a "geração $Y$ ", que compreende idades entre 18 e 30 anos, são produtos de pais workholics, por isso essa geração é carateristicamente superprotegidos e interessados em tecnologia para suprir a ausência dos pais (SANTOS, 2011).

Esse predomínio da geração $X$ em relação à $Y$ vai de encontro ao observado no ano de 2015 na cidade de Sorocaba, onde existe um equilíbrio entre as gestantes das gerações $X$ e $Y$. Esse fator evidencia que a população atendida no curso para pais grávidos corresponde a um grupo mais maduro, o que condiz com o dado encontrado em relação à escolaridade em que a maioria tem ensino superior e pós-graduação, determinando que a mulher engravide mais tardiamente, devido às suas perspectivas de vida profissional (PESSOA, 2016). Provavelmente, tal fato se deve ao perfil do público atendido pela Unimed de Sorocaba que corresponde a um plano de saúde de custo relativamente elevado, com predomínio de pacientes de classe média e de perfil econômico superior. Corrobora para esta hipótese o grande número $(87 \%)$ de mulheres nulíparas no grupo. 
Os participantes souberam do curso, principalmente por meio eletrônico (48,40\%, pela internet) ou através de familiares (25,90\%); $16,10 \%$, por folhetos; $6,40 \%$, por meio de amigos e 3,20\% por outros meios. Quanto ao fato de já ter frequentado um curso de gestante, 96,80\% disseram nunca ter frequentado e 3,20\% já foram a um anteriormente. Em relação ao período gestacional, 6,25\% das gestantes estavam no primeiro trimestre; 43,75, no segundo trimestre; e 50\%, no terceiro trimestre gestacional.

Em relação ao acompanhamento de consulta de pré-natal pelo parceiro, 66,70\% sempre acompanham a consulta; 19,50\%, na maioria das vezes; $19,90 \%$, às vezes; e $6,70 \%$ nunca acompanham. Com referência a acompanhar o momento do parto, todos os acompanhantes relataram que fariam isso.

A nova visão educativa sobre a assistência pré-natal, que surgiu a partir das propostas de humanização do parto, faz com que os parceiros participem das atividades e acompanhem as gestantes nas consultas, nesse período muito especial da vida do casal, que traz sentimentos ambíguos de felicidade e, ao mesmo tempo, medo e angústia (ZANGALLI; POLONI; LANG, 2016). A humanização do parto tem associação com a atenção qualificada do empoderamento da mulher e garantia de autonomia na experiência obstétrica (GOMES, 2012). No presente estudo, todos os parceiros desejavam assistir ao parto, o que traz benefícios por gerar segurança, encorajamento, tranquilidade, felicidade e fortalecimento familiar, tornando o parto uma experiência positiva (SINGATA, 2010). A participação do companheiro na gravidez faz com que este se sinta parte do processo gestacional, que promove relações menos conflituosas com a companheira, refletindo na qualidade de vida do casal (SANTOS, 2011).

No questionário final, aplicado após o curso, foi perguntado quais temas foram abordados. O tema "orientações sobre a gestação" foi citado por 83,80\% dos depoentes, que afirmaram que este assunto foi tratado e, para $16,20 \%$, não houve a abordagem do assunto na atividade daquele dia. Quanto às orientações sobre as doenças que podem acontecer na gestação, 32,20\% afirmaram ter sido abordado. Sobre as orientações relativas aos exames do pré-natal, 22,50\% afirmaram que houve tal discussão. A respeito das orientações sobre e ao tipo de parto, todos afirmaram ter ocorrido. Acerca de aprender sobre os primeiros cuidados com o recém-nascido, 96,70\% declararam que houve isso. A propósito de conhecer como funciona a assistência ao parto na Unimed Sorocaba, $77,40 \%$ disseram que esse assunto foi apresentado. Com relação ao conhecimento da existência de cobrança de honorários dos médicos para assistir as gestantes (honorários para disponibilidade), 93,60\% relataram que isso não ocorreu. Sobre o fato de reconhecer quando se deve ir ao hospital, todos declararam que isso foi esclarecido. A respeito de aprender maneiras não medicamentosas de diminuir a dor do parto, somente 19,30\% disseram que esse assunto foi abordado. 
Tabela 1 - Temas apresentados no curso para pais grávidos.

\begin{tabular}{|c|c|c|c|}
\hline & Antes & Depois & Hipótese \\
\hline Orientações sobre a gestação normal & 1 & 1,32258 & Significante \\
\hline $\begin{array}{l}\text { Orientações sobre as doenças que podem } \\
\text { acontecer na gestação }\end{array}$ & 1,1290 & 1,1290 & Não significante \\
\hline Orientações sobre os exames do pré-natal & 1 & 1,06451 & Não significante \\
\hline Orientações sobre o parto & 1,2258 & 1,54838 & Significante \\
\hline $\begin{array}{l}\text { Aprender sobre os primeiros cuidados com o } \\
\text { recém-nascido }\end{array}$ & 1,0645 & 1,4516 & Significante \\
\hline $\begin{array}{l}\text { Conhecer como funciona a assistência ao parto na } \\
\text { Unimed Sorocaba }\end{array}$ & 1,6129 & 1,6451 & Significante \\
\hline $\begin{array}{l}\text { Saber se existe disponibilidade do obstetra para } \\
\text { assistir às suas gestantes }\end{array}$ & 0,6129 & 1,2258 & Significante \\
\hline $\begin{array}{l}\text { Reconhecer quando deve ir ao hospital para dar a } \\
\text { luz }\end{array}$ & 0,67741 & 0,61290 & Não significante \\
\hline $\begin{array}{l}\text { Aprender maneiras não medicamentosas de } \\
\text { diminuir a dor do parto }\end{array}$ & 1,29032 & 1,58064 & Significante \\
\hline $\begin{array}{l}\text { Aprender maneiras não medicamentosas de } \\
\text { diminuir a dor do parto }\end{array}$ & 1,03225 & 0,77419 & Não significante \\
\hline
\end{tabular}

Fonte: Os autores (2017).

No estudo de SANTOS (2011), foi descrito que as maiores dúvidas dos casais referem-se ao parto e sobre o momento de se dirigirem ao hospital. O mesmo se verificou em nossa casuística e, no presente trabalho, houve constatação que o curso se prestou para melhorar a compreensão dos casais sobre este assunto após o terem assistido, o que mostra o alinhamento da aula com as demandas dos clientes. Um assunto praticamente não abordado foi a disponibilidade obstétrica, que, desde 2007, vem sendo discutida entre médicos, operadoras de saúde, Agência Nacional de Saúde (ANS) e Conselho Federal de Medicina (CFM). O assunto diz respeito à cobrança de honorário pelo obstetra para realizar todo o acompanhamento pré-natal e o parto, prestando um atendimento exclusivo. Oficializado por meio de parecer do CFM no 39/12, que relatou ser legal, seguindo o Parecer do CFM 39/2016, que diz em sua ementa:

É ético e não configura dupla cobrança o pagamento de honorário pela gestante referente ao acompanhamento presencial do trabalho de parto, desde que o obstetra não esteja de plantão e que este procedimento seja acordado com a gestante na primeira consulta. Tal circunstância não caracteriza lesão ao contrato estabelecido entre o profissional e a operadora de plano e seguro de saúde

Esta temática permaneceu oculta no 
curso porque a legitimidade de pagar esta disponibilidade gera muita polêmica entre os casais e também porque o ponto de vista oficial da Unimed de Sorocaba não fora divulgado.

Outra questão que chama a atenção é o fato dos participantes constatarem que as medidas não farmacológicas para diminuir a dor do parto não são tratadas de forma explícita, ou seja, não se fala em como amenizar a dor do parto. Sabe-se que medidas como bola obstétrica, banheira para banho de imersão, chuveiro, deambulação, técnicas de respiração, agachamento e massagens aliviam a dor, mas as pacientes somente poderão demonstrar interesse nessas práticas se receberem alguma informação técnica sobre o assunto (APOLINÁRIO, 2016). É provável que não exista essa discussão nas aulas do curso de pais grávidos porque as profissionais que participam do curso não são aquelas que efetivamente atenderão o parto, pois, na Unimed de Sorocaba, todos os partos são executados pelos obstetras. Uma boa sugestão seria incluir este tema naquilo que é discutido, pois se revelou uma demanda dos pais. A simples orientação sobre o posicionamento durante o trabalho de parto já pode contribuir para abreviar a duração. Parturientes que se locomovem livremente para se acomodarem em uma posição mais confortável durante o trabalho de parto têm um encurtamento do parto quando comparadas as que ficam somente deitadas (SOUZA, 2011).

Em relação aos profissionais, todos aqueles que desenvolveram suas atividades no curso responderam ao questionário. O grupo foi composto por dois enfermeiros, uma secretária e uma nutricionista. Na média, esses profissionais trabalham há um ano e sete meses na Unimed de Sorocaba. No tocante à descrição das atividades que desenvolvem no curso, uma cuida da parte de serviços de secretaria (a própria secretária), três participam das aulas expositivas (enfermeiros e nutricionista) e uma delas acumula a função de elaboração do conteúdo teórico (enfermeira obstetriz). Sobre a avaliação do curso por estes profissionais, $75 \%$ considera o curso muito bom e $25 \%$ apenas bom. Sobre o aproveitamento do curso pelos participantes, os profissionais relatam ser muito bom (75\%) e bom (25\%). Referente à relevância dos temas que deveriam ser abordados durante o curso, os colaboradores consideram que as orientações sobre a gestação normal, as orientações sobre o tipo de parto e conhecer como funciona a assistência ao parto na Unimed Sorocaba têm alta relevância. Sobre as orientações das doenças que podem acontecer na gestação, $75 \%$ relatam ser necessário apresentar este tema no curso e 25\% são indiferentes. Em relação às orientações dos exames de pré-natal, 50\% indicaram relevância alta; 25\%, muito alta; e 25\%, indiferente. Quanto ao fato de aprender sobre os primeiros cuidados com o recém-nascido 50\% consideraram ser alta e os outros 50\% disseram ser muito alta. No que concerne à existência de cobrança de honorários dos médicos para assistir as gestantes, 50\% consideram ser alta e $50 \%$ dizem ser indiferentes. No que concerne reconhecer o momento de ir ao hospital e o fato de aprender maneiras não medicamentosas de diminuir a dor do parto, 75\% acreditam ser alta a relevância e $25 \%$, muito alta.

Aparentemente foram semelhantes os conceitos atribuídos aos temas que efetivamente foram apresentados no curso pelos profissionais responsáveis por ele. Talvez fosse interessante incluir médicos obstetras que, efetivamente, atuam na assistência ao parto, para esclarecer aspectos operacionais dessa assistência, bem como garantir a coerência entre o apresentado e o que efetivamente vai acontecer no momento do parto.

\section{Análise qualitativa}

Apartirdaprovocaçãodoautorsobreasduas questões norteadoras, dois grupos responderam 
às questões: "Como foi para você participar deste curso?" e "Como você espera que seja seu parto?". Os grupos deveriam fazer uma colagem e, posteriormente, apresentar a explicação daqueles elementos, esclarecendo a todos qual foi o sentido que quiseram dar à colagem.

Aos profissionais que participaram da elaboração e apresentação do curso, foi solicitado que desenvolvessem uma colagem com questão norteadora "Como seria o curso de gestantes ideal?". Da mesma forma, em seguida, solicitou-se que descrevessem oralmente aquilo que pretendiam expressar. A partir da interpretação da gravação desses relatos, organizamos os temas subjacentes que nos pareceram mais relevantes (Quadro 1).

Quadro 1 - Distribuição da interpretação dos relatos relativos às questões norteadoras aos participantes gestantes/acompanhantes e profissionais que ministraram o curso.

\begin{tabular}{|l|l|}
\hline Questão norteadora $1-$ grupo 1 & Insegurança e ansiedade \\
\hline Questão norteadora 1 - grupo 2 & Insegurança \\
\hline Questão norteadora 2 - grupo 1 & Medo \\
\hline Questão norteadora 2 - grupo 2 & Racionalização e fuga \\
\hline Questão dirigida aos profissionais & Eficácia, divergência e aperfeiçoamento \\
\hline
\end{tabular}

Fonte: Os autores (2017).

O curso para pais grávidos da Unimed Sorocaba aborda, de forma ampla, aspectos gestacionais e de cuidados com o recém-nascido indo ao encontro das diretrizes do Programa de Humanização do Parto e Nascimento, instituído pelo Ministério da Saúde em 2002 (BRASIL, 2002), procurando desmistificar alguns tabus e dizeres populares (LOPES, 2015). Após o curso, ficou evidente uma mudança de perspectiva dos pais participantes sobre alguns dos temas, como orientação sobre gestação, parto e tipo de parto; aprendizagem sobre os primeiros cuidados com o recém-nascido; conhecimento sobre como funciona a assistência ao parto na Unimed Sorocaba; e o reconhecimento de quando se deve ir ao hospital. No que concerne à sucinta análise qualitativa dos relatos dos participantes do curso, verifica-se alguns sentimentos como insegurança e medo presentes mesmo após a aula. Isso, em parte, contradiz o estudo de SANTOS (2011), em que, após a palestra, a maior parte das pessoas estava mais segura e com menos medo do processo gestacional e parto.

Uma proposta para as novas edições deste curso seria abordar o parto de forma clara, isto é, discorrer sobre as medidas não farmacológicas para alívio da dor no parto, tema obscuro nesse momento crucial, além de procurar esclarecer sobre as técnicas que podem ser realizadas nesse período, desmistificando a temida dor do parto.

Outro assunto que poderia ser elucidado no curso seria a cobrança de disponibilidade pelos obstetras, discorrendo sobre a legislação e esclarecendo esse polêmico assunto que gera conflito entre clientes, médicos e operadora.

Como proposta adicional, foi citado pelas gestantes e pelos colaboradores que seria interessante fracionar o curso por período gestacional, pois havia gestantes dos três trimestres e certos assuntos como nutrição, por exemplo, já não ofereciam tanto interesse àquelas em fim de gestação. 
Um questionamento dos palestrantes é sobre o desencontro de informação entre as instituições da Unimed Sorocaba, ou melhor, não existe um alinhamento entre a consulta médica, o hospital e o que é apresentado na palestra, ocasionando, após o parto, um desencontro de informações, principalmente no que concerne à amamentação. Uma sugestão seria a padronização dos temas nos três setores, no intuito de beneficiar as pessoas. Contudo, esta sugestão será de difícil operacionalização em um serviço que funciona nos moldes de cooperativa, pois a conduta médica é algo nem sempre comum a todos os especialistas.

A palestra atualmente é apresentada de forma tradicional, ou seja, cada tema é exposto por meio de slides, o que faz com que os participantes fiquem passivos no processo de aprendizagem, tornando o curso cansativo muitas vezes. Uma alternativa seria a formação de grupos, promovendo a tempestade de ideias sobre determinado assunto. Assim, os participantes poderiam relatar seus conhecimentos e o grupo, dirigido pelo palestrante, que seria uma espécie de tutor, criaria um novo conceito conjuntamente. Nesse sentido, a prática de colagem em grupos permite maior integração e descontração, funcionando como catalisador de roda de conversa coordenadapeloprofissionalqueministra ocurso.

O questionário sobre os assuntos de interesse deveria ser aplicado previamente e após o curso para se ter uma ideia do aproveitamento das pessoas e se a expectativa dos participantes foi suprida.

Como fechamento do curso, poderia se criar uma roda de dúvidas, tendo como catalisador a atividade prática das colagens, tendo, neste momento, um médico como conselheiro para esclarecer os questionamentos finais com o grupo a fim se criar um conhecimento coletivo, vindo de todos.

Em suma, o curso para pais grávidos da Unimed Sorocaba é bem estruturado e, de certa forma, corresponde à expectativa dos participantes, conseguindo esclarecer as principais dúvidas deste momento muito especial do casal.

Uma proposta para aprimorar a atividade seria a implantação, ao fim da apresentação, de núcleos de discussão que poderiam ser realizados através das colagens realizadas nessa pesquisa, o que serviria como estímulo a discussões abertas para construção coletiva de um novo saber.

\section{Referências}

ALBERTI, G. F. et al. Educação popular trabalhada em oficinas de saúde: a sexualidade durante o adolescer. Rev. Educ. Popular, Uberlândia, v. 13, n. 1, p. 75-81, jan.-jun. 2014. Disponível em: <http://www.seer.ufu.br/index.php/reveducpop/article/view/24871>. Acesso em: 16 mar. 2016.

ALMEIDA, J. M. Projeto vertical zero: expectativas e ações de pais soropositivos para o HIV à espera do diagnóstico do filho. 2008. 183f. Tese (Doutorado em Enfermagem) - Universidade de São Paulo, 2008.

APOLINÁRIO, D. et al. Práticas na atenção ao parto e nascimento sob a perspectiva das puérperas. Rev. RENE, Fortaleza, v. 17, n. 1, p. 20-28, 2016. doi: http://dx.doi.org/10.15253/rev\%20rene. v17i1.2601.

BLAXTER, M. Life narratives, health and identity. In: KELLEHER, D; LEAVEY, G. (Eds.) Identity and health. London: Routledge, 2004. p. 170-99. 
BOEHS, A. E. et al. Interface necessária entre enfermagem, educação e saúde e o conceito de cultura. Texto Contexto Enferm [online], Santa Catarina, v.16, n. 2, p. 307-314, abr.-jun. 2007. doi: http://dx.doi.org/10.1590/S0104-07072007000200014.

BRASIL. Ministério da Saúde. Secretaria de Políticas de Saúde. Área de trabalho de Saúde da Mulher. Parto, aborto e puerpério: assistência à mulher. Brasília, DF: MS, 2001. p. 14-19.

FREIRE, P. Pedagogia da autonomia: saberes necessários à prática educativa. São Paulo: Paz e Terra, 1996.

GAZZINELLI, M. F. et al. Educação em saúde: conhecimentos, representações sociais e experiências da doença. Cad. Saúde Pública, Rio de Janeiro, v. 21, n. 1, jan.-feb. 2005. doi: http://dx.doi. org/10.1590/S0102-311X2005000100022.

GENIAKE, L. M. V; LIMA, J. A. S. L; LOURENÇO, L. D. Z. Oficinas educativas com gestantes: uma intervenção na unidade de saúde da família. Rev. Educ. Popular, Uberlândia, v. 14, n. 1, p. 136-144, jan.-jun. 2015. Disponível em: <http://www.seer.ufu.br/index.php/reveducpop/article/ view/27542>. Acesso em: 20 maio 2016. doi: http://dx.doi.org/10.14393/REP-v14n12015-rel01.

GOMES, L. F. S. et al. Reflections on the promotion of health in the context of the program humanization prenatal and birth. Journal of Nursing, Recife, v. 6, n. 7, 2012. Disponível em: http://www.revista.ufpe.br/revistaenfermagem/index.php/revista/article/view/2659. Acesso em: 10 jun. 2016.

LOPES, L. G. et al. Curso de gestantes e parto humanizado: contribuições para o enfermeiro. Extensão em Ação, Fortaleza, v. 2, n. 9, p. 80-87, 2015. Disponível em: <http://www.revistaprex. ufc.br/index.php/EXTA/article/view/240>. Acesso em: 16 mar. 2017.

MAFFESOLI, M. No fundo das aparências. Petrópolis (RJ): Vozes, 1996.

MINAYO, M. C. S. O desafio do conhecimento: pesquisa qualitativa em saúde. 7. ed. São Paulo: Hucitec, 2000.

MOREIRA, C. T.; MACHADO, M. F. A. S.; BECKER, S. L. M. Educação em saúde a gestante utilizando a estratégia de grupo. Rev. RENE, Fortaleza, v. 8, n. 3, p. 107-116, set./dez. 2007.

OLIVEIRA, S. M. J. V. et al. Tipo de parto: expectativas das mulheres. Rev. Lat-Am. de Enfermagem, Ribeirão Preto, v. 10, n. 5, p. 667-674, set-out. 2002. doi: http://dx.doi.org/10.1590/S010411692002000500007.

PESSOA, L. 13,5\% das crianças são de mães adolescentes. Jornal Cruzeiro do Sul, Sorocaba, 29 nov. 2016. Disponível em: <http://www.jornalcruzeiro.com.br/materia/747847/135-das-criancasnascidas-na-rms-sao-de-maes-adolescentes.html>. Acesso: 28 mar. 2017.

REZENDE, J. Obstetrícia. 10. ed. Rio de Janeiro: Guanabara Koogan, 2001. 1104 p.

SAMPAIO NETO, L. F.; ALVARES, L. B. O papel do obstetra e do psicólogo na depressão pós-parto.

Rev. Fac. Cienc. Méd. de Sorocaba, Sorocaba, v, 15, n. 1, p. 180-183, Disponível em: < https:// revistas.pucsp.br/index.php/RFCMS/article/view/13171>. Acesso em: 10 mar. 2017. 
SANTOS, F., C. et al. O processo evolutivo entre as gerações $\mathbf{X}, \mathbf{Y}$ e baby boomers. In: SEMINÁRIOS EM ADMINISTRAÇÃO, 14., out. 2011, São Paulo. Disponível em: < https://originaconteudo.com. br/arquivos/Artigo-geracoes-X-Y-e-Baby-boomers.pdf>. Acesso em 10 mar. 2017.

SANTOS, R. V.; PENNA, C. M. M. Integralidade do cuidado à gestante, puérpera e recém-nascido: o olhar de usuários. Texto Contexto Enferm., Florianópolis, v. 18 n. 4, p. 652-660, 2009.

SCHIRMER, J. et al. Incentivando o parto normal. In: BARROS, S. M. O. de; MARIN, H. F.; ABRÃO, A. C. F. Enfermagem obstétrica e ginecológica: guia para a prática assistencial. São Paulo: Roca, 2002. p. 203-210.

SOUZA, V. B.; ROECKER, S.; MARCON, S. S. Ações educativas durante a assistência pré-natal: percepção de gestantes atendidas na rede básica de Maringá- PR. Revista Eletrônica de Enfermagem, Goiânia, v. 13, n. 2, p. 199-210, 2011. doi: http://dx.doi.org/10.5216/ree.v13i2.10162.

STRAPASSON, M. R., SILVA, E. V., FISHER, A. C. S. Métodos não farmacológicos de alívio da dor durante trabalho de parto e parto. REUFSM, Santa Maria, v. 1, n. 2, p. 261-271, 2011. doi: http:// dx.doi.org/10.5902/217976922526.

TEDESCO, R. P. et al. Fatores determinantes para expectativas das primigestas acerca da via de parto. Rev. Bras. Ginecol. Obstet., Rio de Janeiro, v. 26, n. 10. nov.-dec. 2004. doi: http://dx.doi. org/10.1590/S0100-72032004001000006.

ZAMPIERI, M. F. et al. Processo educativo com gestantes e/ou casais grávidos: possibilidade de reflexão para transformação e reflexão da realidade. Texto Contexto Enferm., Florianópolis, v. 19, n. 4, p. 719-727, out.-dez. 2010.

ZANGALLI, C.; POLONI, P. G. P.; LANG, C. S. Grupo de gestantes. In: CONGRESSO DE PESQUISA E EXTENSÃO DA FACULDADE DA SERRA GAÚCHA, 4., 2016, Caxias do Sul. Anais... Disponível em: <http://ojs.fsg.br/index.php/pesquisaextensao/article/view/2301>. Acesso em: 22 mar. 2017.

Submetido em 23 de janeiro de 2017

Aprovado em 20 de março de 2017. 